\title{
Design of Miniaturized Multiband Microstrip Patch Antenna using Defected Ground Structure
}

\author{
Mudasar Rashid ${ }^{1}$, Mehre E Munir ${ }^{2}$, Jehanzeb Khan ${ }^{4}$ \\ Dept. of Electrical Engineering \\ Iqra National University \\ Peshawar, Pakistan
}

\author{
Khalid Mahmood ${ }^{3}$ \\ Dept. of Electrical Engineering \\ University of Technology, \\ Nowshera, Pakistan
}

\begin{abstract}
The recent developments in communication and antenna engineering demands compact and multiband antennas. Microstrip antenna is one of the most useful antennas for wireless communication because of its inherent features like low profile, light weight and easy fabrication. This design is aimed at miniaturized Microstrip Patch Antenna (MSA), without deteriorating its other parameters, such as gain, bandwidth, directivity and return loss. A significant amount of $89 \%$ miniaturization has been made possible by careful and meticulous investigation of slots insertion in patch and ground of MSA antenna. Dielectric substrate used in this design is polyester which has shown better result. As the focus of this design is to miniaturize the MSA, the technique used here is Defected Ground Structure (DGS), along with Defected Patch Structure (DPS) which actually shifted the resonant frequencies to the lower range without increasing its physical dimensions. Besides this shorting pin is also introduced between patch and ground, which also contributed in the enhancement of parameters like gain and return loss. The position of pin played an important role in the acquirement of better performance and radiation at desirable frequency band. Different shapes have been designed on Ground and Patch to obtain enhanced results. With the use of DGS, the designed antenna started radiation at multiple frequency bands. The frequency bands generated by this designed antenna are in the range of $L$ band and $S$ band of IEEE standard which made it apposite to use in variety of applications.
\end{abstract}

Keywords-Miniaturization; multiband; defected ground structure (DGS); defected patch structure (DPS); directivity; gain

\section{INTRODUCTION}

In contemporary world, where the space technology is booming with very high pace, require the hardware which is of small size and high efficiency. The antenna is the integral part of the wireless communication and it also required to be low profile with high efficiency and improved parameters. Low profile antennas are regularly used in various commercial and public applications such as radio, mobile and wireless communication wherein size of the antenna is matter of concern [1]. For this purpose Microstrip Antenna (MSA) is unvaryingly used. MSA is well-matched with MMIC design.

The microstrip patch antenna is majorly consist of patch, substrate and ground mounted one above other in a layer making three slices, along with this there is feeding part also connected on the suitable place [2]. The dimension of patch and ground of MSA can be exploited to get more affirmative variation in different parameters like resonant frequency, radiation pattern, gain, efficiency and directivity. Moreover when certain load is inserted, such as pins and varactor diode, between the patch and ground, results in variation of parameters values [3].

Major drawbacks in operation of MSA are low power gain, low efficiency, spurious feed radiation and narrow bandwidth [4]. However, in certain application like security systems narrow frequency bandwidth is considered advantageous. Also there are certain techniques to enhance the bandwidth and efficiency i.e. increasing the substrate's height. However, at the same time as the height increase it extracts more power for direct radiation because of introducing of surface wave which is again undesirable. These surface waves in return radiate at discontinuity or bands and result in the degradation of polarization characteristic and antenna pattern. Defected Ground Structure (DGS) is useful in suppressing cross polarization [5]. By introducing cavity or any shape the surface wave can be removed while bandwidth remains as improved. Stack configuration is also use to enhance the bandwidth. DGS technique is used to achieve size reduction and also further bandwidth as well as gain enhancement. Artificial magnetic conductor has been used for the antenna's miniaturization and reduction of antenna size has achieve but at the cost of lower gain [6]. Introduction of Koch fractal shape on the patch also reduce the size of antenna up to $21 \%$ but the gain starts decreasing after few iteration [7]. One more technique of short circuiting the patch to ground of MSA is introduced for miniaturization but again the problem happened with the gain [8]. The main drawback of smaller physical dimensioned antenna is that it has narrow impedance bandwidth. Multiband response is introduced in MSA antenna but yet again the gain is remained problem [9]. Miniaturization has been accomplished by using complementary split ring resonators, wherein the size reduced up to $10 \%$ [10]. For the reduction of size of antenna Meta material is used for ground plane along with high permittivity substrate which results in considerable antenna reduction but at the cost of poor efficiency and narrow impedance bandwidth of antenna [11]. This task can also be performed by substrate of pure magnetic property but finding pure magnetic material is demanding to obtain [12]. Defected ground structure is already investigation in microstrip patch antenna for miniaturization purpose and till then the reduction of antenna achieved was 34\% [13]. Arrangement of L-Shape and U-Shape slits on the Ground plane are also used for miniaturization of antenna wherein impedance bandwidth is in range of $3.1 \%-25 \%$ [14]. Patch and the ground plane are 
shorted through a shorting pin and ground plane are disturbed for miniaturization and has acceptable gain for all band which is in the range of $3.5 \mathrm{dBi}$ to $6.6 \mathrm{dBi}$ [15]. When MSP antennas are used in low frequency band the size of antenna get increased.

A particular inset-fed MSA has generated resonant frequency of $3.6 \mathrm{GHz}$ wherein defected ground structure makes the frequency band shifted towards a lower frequency, in doing so miniaturization of the MSA antenna is justified [16]. Defected ground structure is incorporated with defected patch antenna to improve its performances and achieve miniaturization but miniaturization up to $50 \%$ was achieved, comparing with conventional microstrip antenna [17]. Electromagnetic band gap (EBG) structure is used like defect ground structure to miniaturize and attain multiband resonant frequencies. Two cells of spiral-shaped defected ground structure (DGS) with each cell composed of spiral with four arms are used in the design. Simulations outcome showed that $50 \%$ reduction in size was accomplished [18], [19]. Without defected ground structure and other slots the antenna resonates at $3.22 \mathrm{GHz}$ but after the DGS and slots introduced in MSA the frequency shift from $3.22 \mathrm{GHz}$ to $1.07 \mathrm{GHz}$ [20]. DGS technique is also used for array microstrip patch antenna size reduction wherein the miniaturization achieved is $37 \%$ [21].

\section{ANTENNA CONFIGURATION}

In designing microstrip patch antenna the first and foremost task is to measure the dimension of antenna for specific frequency and substrate. For dimension, the parameters required are length of patch $\left(\mathrm{P}_{\mathrm{L}}\right)$, width of patch $\left(\mathrm{P}_{\mathrm{W}}\right)$, length of ground $\left(G_{L}\right)$, width of ground $\left(G_{W}\right)$, height of substrate $\left(S_{H}\right)$. It is also a matter of concern to find the proper feed location on antenna as it ensures the better impedance matching. Feeding point is point on antenna where antenna is made excited by input energy. The suitable feeding point on antenna is where the input impedance matches the antenna impedance.

Before finding other parameters of antenna for its dimension, it's important to set following three parameter on the basis of which other parameters have to derive.

\section{A. Operating Frequency}

To find out the length, height and width of antenna, it's imperative to choose a desired frequency for which antenna has to be design. For this specific MSA design the frequency that has been chosen is $4.1 \mathrm{GHz}$.

\section{B. Dielectric Substrate}

Dielectric substrate plays an important role in defining MSA antenna design. Here, in this design the substrate used is "Polyester". This dielectric substrate has very low relative permittivity of about 1.39 .

\section{Substrate Height $\left(H_{S}\right)$}

Since the miniaturization of an antenna is the major objective of this design, so the thickness of dielectric substrate is kept such that the goal is achieved without disregarding other parameters such as bandwidth, gain, and efficiency. As the bandwidth is related to thickness of substrate, trade-off has been made between miniaturization and other parameters i.e. bandwidth. Height of substrate in this particular design is kept $2 \mathrm{~mm}$.

Thus, this design is based on following parameters

Frequency $=4.1 \mathrm{GHz}$

Dielectric substrate permeability, $\varepsilon_{\mathrm{r}}=1.39$

$\mathrm{H}_{\mathrm{S}}=2 \mathrm{~mm}$

\section{Calculating Design Parameters}

On the basis of these above mentioned factors other designed parameters of planned antenna have to be calculated. These designed parameters include length of patch $\left(\mathrm{P}_{\mathrm{L}}\right)$, width of patch $\left(\mathrm{P}_{\mathrm{W}}\right)$, length of ground $\left(\mathrm{G}_{\mathrm{L}}\right)$, width of ground $\left(\mathrm{G}_{\mathrm{W}}\right)$, Effective Dielectric Constant $\left(\varepsilon_{\text {reff }}\right)$, Effective Length $\left(\mathrm{L}_{\mathrm{eff}}\right)$, Length Extension $(\Delta \mathrm{L})$ and Feed Location $\left(\mathrm{X}_{\mathrm{F}}, \mathrm{Y}_{\mathrm{F}}\right)$. Moreover, shorting pin is also used in this design at different location endeavoring for better results.

\section{A. Width of Patch $\left(P_{W}\right)$ Width of Ground $\left(G_{W}\right)$}

The width of patch of design MSA is computed by the expression 1 given below:

$P_{W}=\frac{C}{2 f_{0} \sqrt{\frac{\varepsilon_{r}+1}{2}}}$

Whereas, $\mathcal{E}_{r}=1.3$, speed of light, $\mathrm{c}=3 \times 10^{8} \mathrm{~m} / \mathrm{s}$ and Frequency $f_{0}=4.1 \mathrm{GHz}$ and by putting the values of variables in right side of expression, the width of patch is calculated as; $\mathrm{P}_{\mathrm{W}}=33 \mathrm{~mm}$

The width of ground is greater than width of patch $\left(\mathrm{P}_{\mathrm{W}}\right)$ by simply addition of length equal to six time thickness of substrate (6h) and is given as

$G_{W}=6 h+P_{W}$

By inserting the values of unknowns in right side of equation we get the width of ground as $G_{W}=47 \mathrm{~mm}$

\section{B. Effective Dielectric Constant (creff)}

The effective dielectric constant $\varepsilon_{\text {eff }}$ is given by expression:

$\varepsilon_{e f f}=\frac{\varepsilon_{r}+1}{2}+\frac{\varepsilon_{r}-1}{2}\left[1+12 \frac{h}{P_{W}}\right]^{-\frac{1}{2}}$

Putting the values of variables as $\varepsilon_{r}=1.39, \mathrm{P}_{\mathrm{W}}=33 \mathrm{~mm}$ and $\mathrm{h}=2 \mathrm{~mm}$, the resulting effective dielectric constant will be as under: $\varepsilon_{e f f}=1.344$

\section{Length of Patch $\left(L_{P}\right)$ and Length of Ground $\left(G_{L}\right)$}

Equation for the effective length of patch is given as:

$L_{P e f f}=L_{P}+2 \Delta L_{P}$

$L_{P}=L_{P e f f}-2 \Delta L_{P}$

By inserting the values of $\mathrm{L}_{\text {Peff }}=31.95 \mathrm{~mm}$ and $\Delta \mathrm{L}=$ $1.2096 \mathrm{~mm}$, consequential Length of Patch is derived as: $\mathrm{L}_{\mathrm{P}}=$ $29.53 \mathrm{~mm}$ 


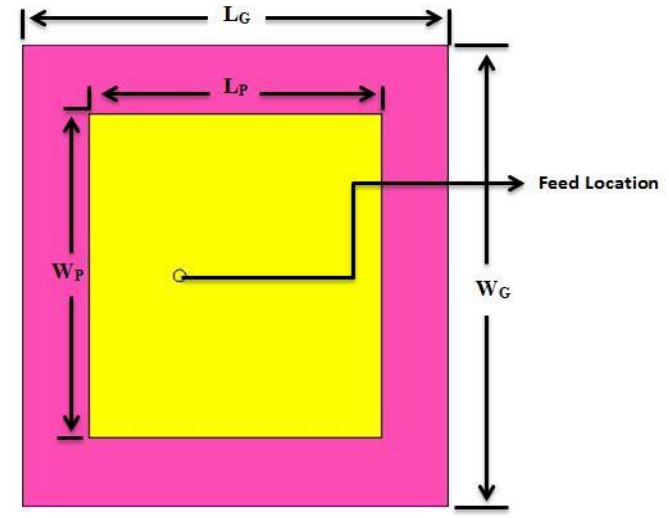

Fig. 1. Front view of conventional MSA.

Likewise the length of ground, the length of ground is also greater than width of patch $\left(\mathrm{P}_{\mathrm{L}}\right)$ by simply addition of length equal to six time thickness of substrate (6h) and is given as

$\mathrm{G}_{\mathrm{L}}=6 \mathrm{~h}+\mathrm{P}_{\mathrm{L}}$

By inserting the values of unknowns in right side of equation we get the width of ground as $\mathrm{G}_{\mathrm{L}}=42 \mathrm{~mm}$.

\section{Feed Scheme and Feed Point $\left(F_{X}, F_{Y}\right)$}

In this design the feeding technique used is coaxial probe feeding. The coaxial probe feeding method is frequently used in microstrip patch antenna. The outer conductor of coaxial probe is connected to the ground plane while inner conductor is drilled into the dielectric substrate and extended outside soldered to radiation patch. The inner and out conductor of coaxial cable are insulated.

The feeding location also plays an important role in impedance matching of antenna. The feed location $\left(\mathrm{F}_{\mathrm{X}}, \mathrm{F}_{\mathrm{Y}}\right)$ are calculated by using following expression:

$F_{X}=\frac{P_{L}}{\sqrt{\varepsilon_{e f f}}}$

$F_{Y}=\frac{P_{W}}{2}$

Using above expression the feed location calculated are FX $=12.73 \mathrm{~mm}$ and $\mathrm{FY}=16.94 \mathrm{~mm}$. Because of the slots insertion the feeding point will slightly change from the calculated location and new proper location found is $F_{X}=8 \mathrm{~mm}$ and $F_{Y}=$ $16.5 \mathrm{~mm}$. According to these calculated parameters first conventional antenna for $4.1 \mathrm{GHz}$ is designed shown in Fig. 1 . Then slots are inserted on patch and ground structure of that antenna.

\section{E. Defected Patch}

Fig. 2 presents the deformed patch shape of Design MSA wherein inverted double $\mathrm{L}$ shape slots are introduced along with stack configuration. The length of long arm of each $\mathrm{L}$ is $19 \mathrm{~mm}$ and width is $1 \mathrm{~mm}$, while the length of short arm of each $\mathrm{L}$ is $8 \mathrm{~mm}$ and width is of $1 \mathrm{~mm}$. Each $\mathrm{L}$ is inverted and facing toward each other. Besides inverted double L slits, a stack configuration is also introduced. Stack configuration represents cutting at each side of the patch. Opposite sides of the patch are equally slotted, the slits parallel to long arms of $L$ are large i.e. its length is $16.4 \mathrm{~mm}$ and width is $2.5 \mathrm{~mm}$ while the slit parallel to short arm is small whose length is $8.22 \mathrm{~mm}$ and width is $2.5 \mathrm{~mm}$.

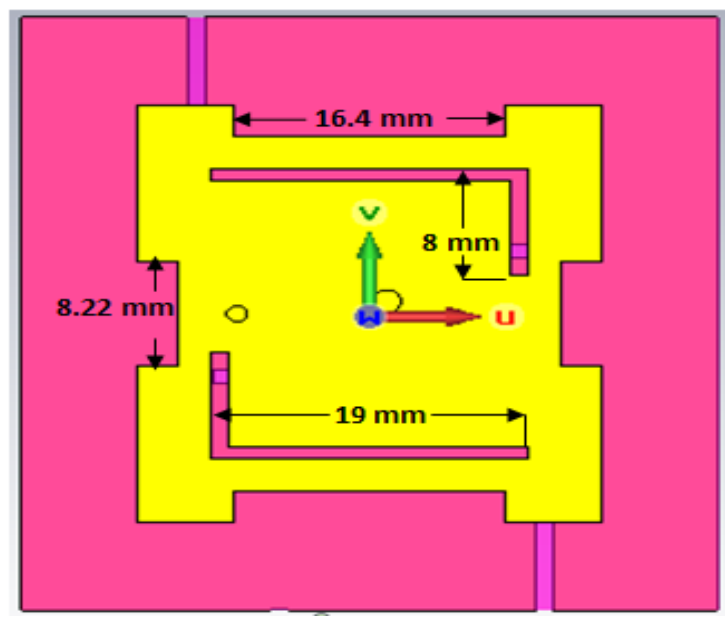

Fig. 2. Defected patch of design MSA.

\section{F. Defected Ground}

Fig. 3 presents the defected shape of ground of Design 2 MSA. Likewise the radiation patch of Design 2 the ground is also deform by introducing inverted double $\mathrm{L}$ but this time both $\mathrm{L}$ are not facing each other but lying in same line facing in opposite direction. The long arm of each $\mathrm{L}$ of length $20 \mathrm{~mm}$ and of width $1 \mathrm{~mm}$ each while the short arm of each $L$ is of length $19 \mathrm{~mm}$ and width $1 \mathrm{~mm}$ each.

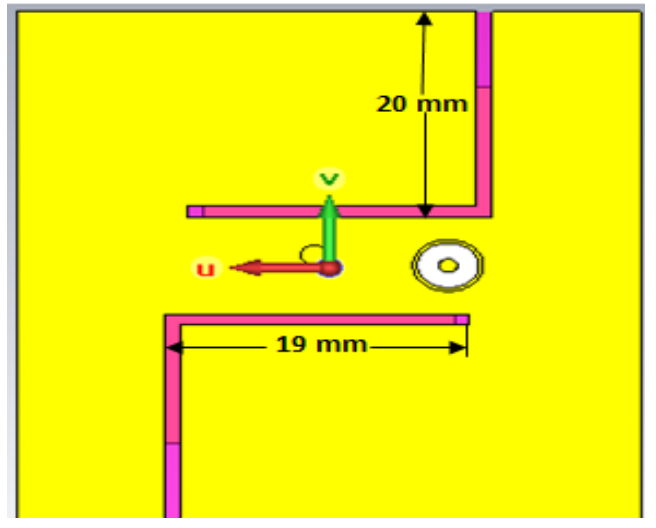

Fig. 3. Defected patch of design MSA.

\section{G. Shorting Pin}

Fig. 4 displayed the bottom view of Design MSA wherein the feeding through coaxial probe is vividly noticeable along with that on the right side of which the shorting pin is visible. Shorting pin short the ground plane with patch for providing low resistive path to current which play an important role in setting parameters of antenna at different frequency band. In side design the best location of shorting pin found is pinU $=1$ and pinV $=1$ (mean $1 \mathrm{~mm}$ in $\mathrm{x}$ direction and $1 \mathrm{~mm}$ in $\mathrm{y}$ direction of local working coordinate system). 


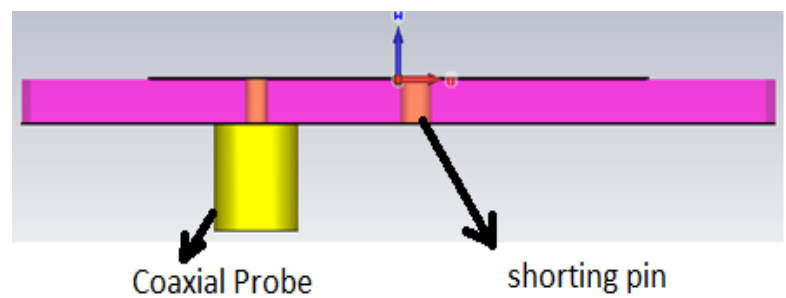

Fig. 4. Shorting pin in design MSA.

\section{RESULTS AND DISCUSSION}

Fig. 5 shows the s-parameter of conventional antenna wherein the antenna is explicitly resonating for only $4.1 \mathrm{GHz}$.
The designed antenna, which is the modification of same antenna that resonated at $4.1 \mathrm{GHz}$, by introducing different shapes on Patch and Ground, is now operating in three different frequency bands shown in Fig. 6.

The S-parameter $(\mathrm{S} 1,1)$ of the Design MSA depict the multiband resonating nature of MSA wherein three different frequency bands show good return losses This designed antenna operates at $1.4 \mathrm{GHz}, 2.2 \mathrm{GHz}$ and $3.88 \mathrm{GHz}$. Return loss of $1.48 \mathrm{GHz}$ is about $-23 \mathrm{~dB}$ and that of $2.24 \mathrm{GHz}$ is almost $18 \mathrm{~dB}$ while that of $3.84 \mathrm{GHz}$ is around $-21 \mathrm{~dB}$. Gain, directivity and Bandwidth at three different frequency bands are given in Table I.

S-Parameter [Magntude in dB]

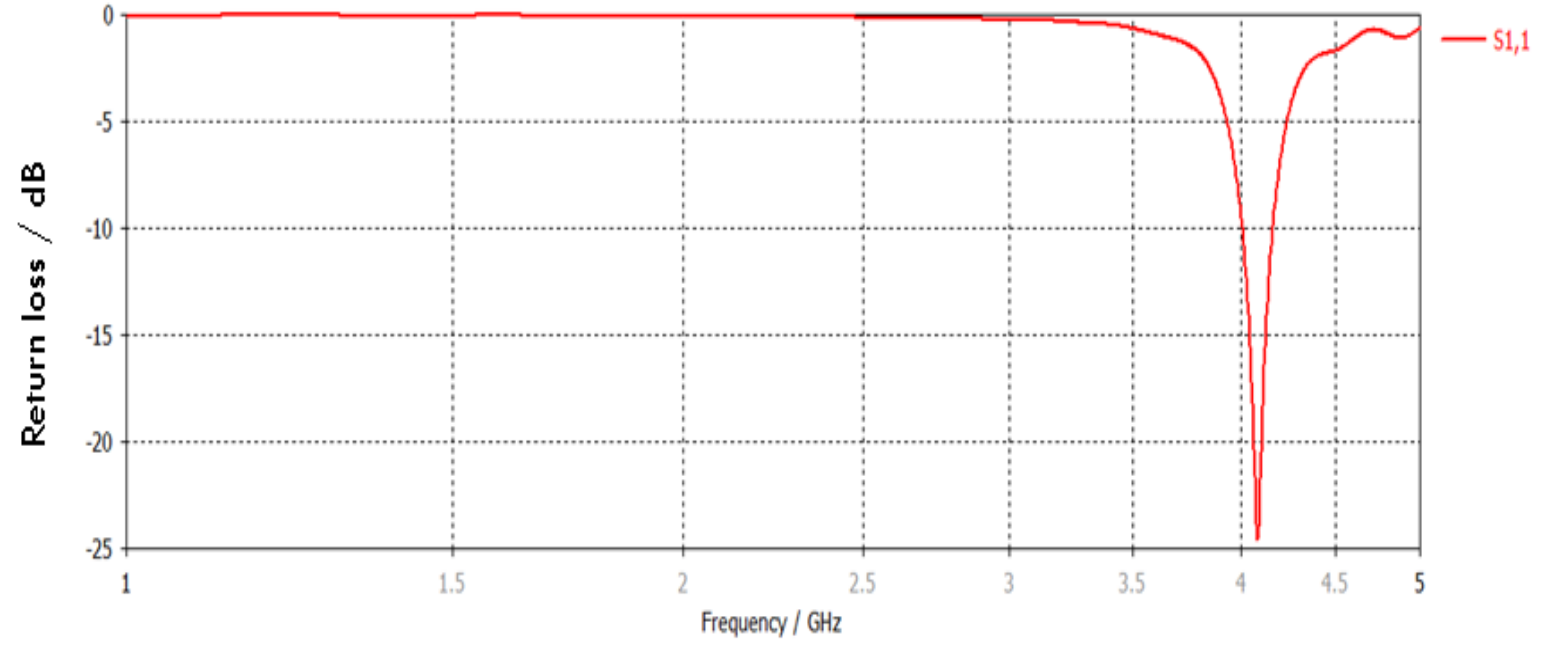

Fig. 5. Return loss in $\mathrm{dB}$ of conventional MSA.

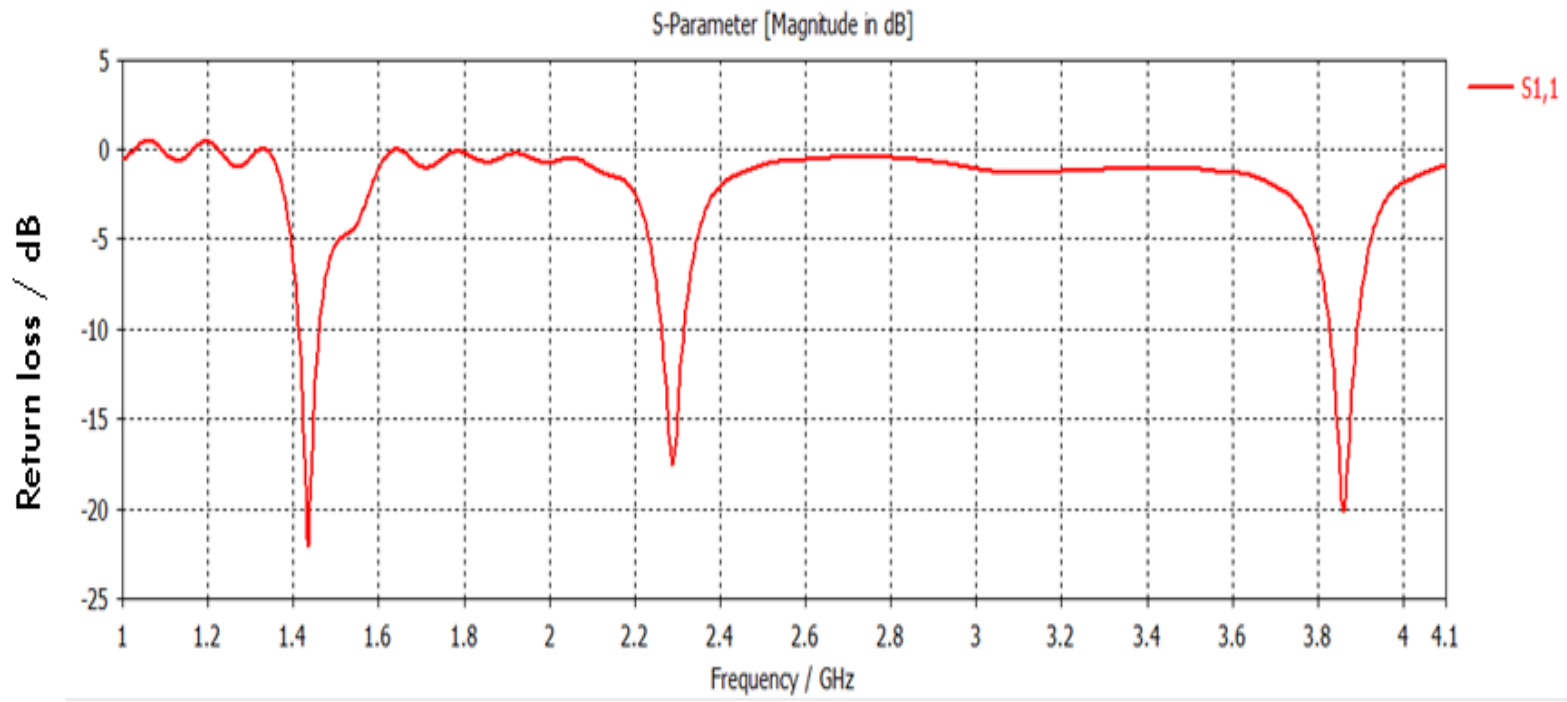

Fig. 6. Return loss in $\mathrm{dB}$ of conventional MSA 
TABLE I. PARAMETERS' VALUE OF DESIGN MSA

\begin{tabular}{|l|l|l|l|}
\hline $\begin{array}{l}\text { Design 2 } \\
\text { MSA } \\
\text { Parameters }\end{array}$ & $\begin{array}{l}\text { Simulation } \\
\text { Results } \mathbf{1}^{\text {st }} \\
\text { frequency band) }\end{array}$ & $\begin{array}{l}\text { Simulation } \\
\text { Results } \mathbf{2}^{\text {nd }} \\
\text { frequency } \\
\text { band) }\end{array}$ & $\begin{array}{l}\text { Simulation } \\
\text { Results } \mathbf{3}^{\text {rd }} \\
\text { frequency } \\
\text { band) }\end{array}$ \\
\hline $\begin{array}{l}\text { Resonant } \\
\text { Frequency }\end{array}$ & $1.48 \mathrm{GHz}$ & $2.24 \mathrm{GHz}$ & $3.84 \mathrm{GHz}$ \\
\hline Return Loss & $-23 \mathrm{~dB}$ & $-18 \mathrm{~dB}$ & $-21 \mathrm{~dB}$ \\
\hline Gain & $4.11 \mathrm{~dB}$ & $4.88 \mathrm{~dB}$ & $6.47 \mathrm{~dB}$ \\
\hline Directivity & $4.2 \mathrm{dBi}$ & $4.95 \mathrm{dBi}$ & $6.69 \mathrm{dBi}$ \\
\hline Bandwidth & $114.3 \mathrm{MHz}$ & $117.8 \mathrm{MHz}$ & $135 \mathrm{MHz}$ \\
\hline
\end{tabular}

Polar pattern of Radiation Gain of Design MSA in the farfield region at resonant frequency $1.48 \mathrm{GHz}$ is show in Fig. 7(a). The Main Lobe magnitude shows maximum gain of $4.11 \mathrm{~dB}$ at $1.48 \mathrm{GHz}$. Polar pattern of Radiation Gain at resonant frequency $2.24 \mathrm{GHz}$ is show in Fig. 7(b). The Main Lobe magnitude shows maximum gain of $4.54 \mathrm{~dB}$ at $2.24 \mathrm{GHz}$ in direction of $89^{\circ}$. Polar pattern of Radiation Gain at resonant frequency $3.84 \mathrm{GHz}$ is show in Fig. 7(c). The Main Lobe magnitude shows maximum gain of $6.43 \mathrm{~dB}$ at $3.84 \mathrm{GHz}$.

Unlike conventional antenna, design antenna radiates at three different useful frequency bands i.e. $1.4 \mathrm{GHz}, 2.24 \mathrm{GHz}$ and $3.84 \mathrm{GHz}$. Since, $1.4 \mathrm{GHz}$ lies in IEEE L band and used for a number of applications. Mobile, military, maritime, land mobile telemetry, fixed telemetry, digital multichannel system, satellite (downlink) and aeronautical are the applications of frequency band $1.4 \mathrm{GHz}$. Moreover, the same final design antenna operates at $2.24 \mathrm{GHz}$ frequency band, which lies in IEEE $\mathrm{S}$ band. This frequency band is also used in some communications satellites. The Design 2 MSA antenna also works at $3.84 \mathrm{GHz}$ which too is present in $\mathrm{S}$ band of IEEE standard.

The Design MSA antenna start operating at lower frequencies simply by defecting ground and patch of antenna rather than increasing its size. This design MSA antenna is miniaturized for $1.4 \mathrm{GHz}$ frequency band up to $89 \%$. For conventional MSA antenna, working at $1.4 \mathrm{GHz}$ frequency, the required dimension would be $98.01 \times 89.10=8732.691 \mathrm{~mm}^{2}$ while the dimension of Design MSA antenna is $33.47 \times 29.14$ $=975.315 \mathrm{~mm}^{2}$. By calculation it is found that Designed antenna is approximately $89 \%$ smaller in size than conventional antenna.
Farfield Gain Abs (Phi=0)

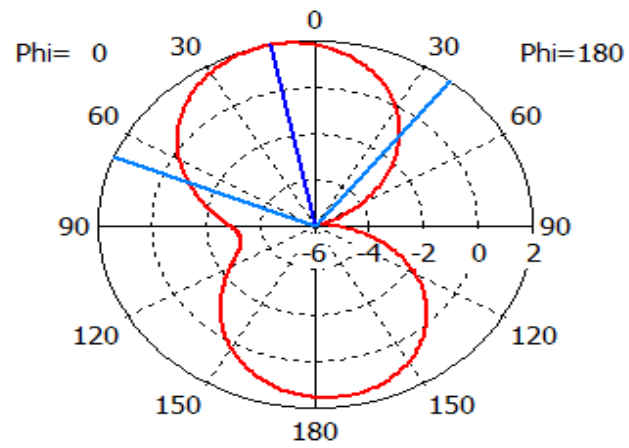

Theta / Degree vs. dB

(a)

Farfield Gain Abs (Phi=0)

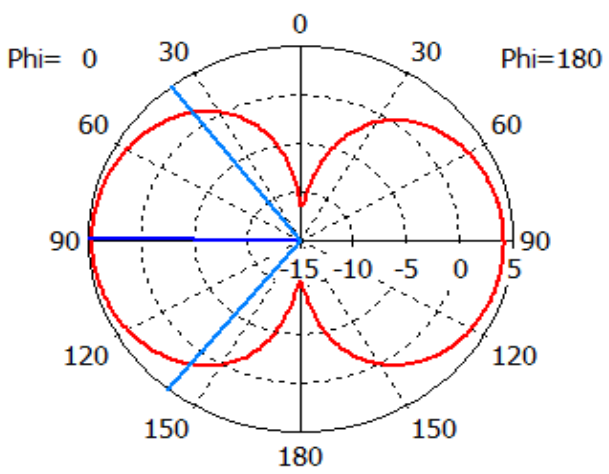

Theta / Degree vs. dB

(b)

Farfield Gain Abs (Phi=0)

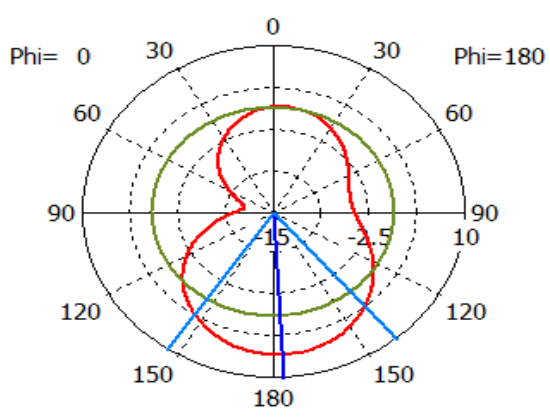

Theta / Degree vs. dB

(c)

Fig. 7. Polar Pattern of Radiation Gain of Design 2 MSA (a) at $1.48 \mathrm{GHz}$ (b) at $2.24 \mathrm{GHz}$ (c) at $3.84 \mathrm{GHz}$ 


\section{CONCLUSION}

A significant amount of $89 \%$ miniaturization has been made possible by careful and meticulous investigation of slot insertion in patch and ground of MSA antenna. After scrutinizing for different designs of cuts on patch and ground plane of MSA, it is made possible to resonate at several frequency bands and produce multiband response. By inserting shorting pin at a proper position between ground and patch, its parameters like gain, directivity and efficiency are improved. The frequency bands generated by this designed antenna are in range of $\mathrm{L}$ band and $\mathrm{S}$ band of IEEE standard. This antenna design is very apposite for application like Mobile, military, maritime, land mobile telemetry, fixed telemetry, digital multichannel system, satellite (downlink) and aeronautical.

\section{REFERENCES}

[1] Z. I. Dafalla, W. T. Y. Kuan, A. Rahman, and S. C. Shudakar. "Design of a rectangular microstrip patch antenna at $1 \mathrm{GHz}$." In RF and Microwave Conference, 2004. RFM 2004. Proceedings, pp. 145-149. IEEE, 2004.

[2] S. Jensen, "Microstrip Patch Antenna." Northern Arizona University (2010).

[3] S. S. Imran Hussain, S. Bashir, and A. Altaf. "Miniaturization of microstrip patch antenna by using various shaped slots for wireless communication systems." In Direct and Inverse Problems of Electromagnetic and Acoustic Wave Theory (DIPED), 2014 XIXth International Seminar/Workshop on, pp. 92-95. IEEE, 2014.

[4] I. Singh, and V. S. Tripathi, "Micro strip patch antenna and its applications: a survey." Int. J. Comp. Tech. Appl 2, no. 5 (2011): 15951599.

[5] G. Debatosh, M. Biswas, and Y. MM Antar. "Microstrip patch antenna with defected ground structure for cross polarization suppression." IEEE Antennas and Wireless Propagation Letters 4, no. 1 (2005): 455-458.

[6] M. Rahmadani and A. Munir, "Microstrip patch antenna miniaturization using artificial magnetic conductor," in Telecommunication Systems, Services, and Applications (TSSA), 2011 6th International Conference on, 2011, pp. 219-223.

[7] S. S. Gaikwad, et al., "Size miniaturized fractal antenna for $2.5 \mathrm{GHz}$ application," in Electrical, Electronics and Computer Science (SCEECS), 2012 IEEE Students' Conference on, 2012, pp. 1-4.

[8] W. Sang-Hyuk, et al., "Wideband Microstrip Patch Antenna With UShaped Parasitic Elements," Antennas and Propagation, IEEE Transactions on, vol. 55, pp. 1196-1199, 2007.

[9] C. Chien-Wen and C. Yu-Jen, "Planar Hexa-Band Inverted-F Antenna for Portable Device Applications," Antennas and Wireless Propagation Letters, IEEE, vol. 8, pp. 1099-1102, 2009.
[10] M. M. Bait-Suwailam and H. M. Al-Rizzo, "Size reduction of microstrip patch antennas using slotted Complementary Split-Ring Resonators," in Technological Advances in Electrical, Electronics and Computer Engineering (TAEECE), 2013 International Conference on, 2013, pp. 528-531.

[11] H. Oraizi and S. Hedayati, "Miniaturization of Microstrip Antennas by the Novel Application of the Giuseppe Peano Fractal Geometries," Antennas and Propagation, IEEE Transactions on, vol. 60, pp. 35593567, 2012.

[12] H. Oraizi and M. Hamidkhani, "Design of miniaturized multi band microstrip antennas with helical slot patterns on patches," in Microwave Conference (EuMC), 2011 41st European, 2011, pp. 257-260.

[13] S. Rezvani, Z. Atlasbaf, and K. Forooraghi. "A novel miniaturized reconfigurable slotted microstrip patch antenna with defected ground structure." Electromagnetics 31, no. 5 (2011): 349-354.

[14] S. S. Imran Hussain, and S. Bashir. "Miniaturization of microstrip patch antenna with multiband response for portable communication systems." In Direct and Inverse Problems of Electromagnetic and Acoustic Wave Theory (DIPED), 2013 XVIIIth International Seminar/Workshop on, pp. 119-123. IEEE, 2013.

[15] S. S. Imran Hussain, S. Bashir, and Amir Altaf. "Miniaturization of microstrip patch antenna by using various shaped slots for wireless communication systems." In Direct and Inverse Problems of Electromagnetic and Acoustic Wave Theory (DIPED), 2014 XIXth International Seminar/Workshop on, pp. 92-95. IEEE, 2014.

[16] J. K. Satish, and G. Shrivas. "Miniaturization of microstrip antennas using defected ground plane." In Recent Advances in Electronics \& Computer Engineering (RAECE), 2015 National Conference on, pp. 149-153. IEEE, 2015.

[17] H. Elftouh, N. A. Touhami, M. Aghoutane, S. E. Amrani, A. Tazon, and M. Boussouis. "Miniaturized microstrip patch antenna with defected ground structure." Progress In Electromagnetics Research C 55 (2014): 25-33.

[18] N. Dalia, A. Hala, E. E. Abdallah, H. Elhenawy, and M. F. Iskander. "Multiband and miniaturized inset feed microstrip patch antenna using multiple spiral-shaped defect ground structure (DGS)." In Antennas and Propagation Society International Symposium, 2009. APSURSI'09. IEEE, pp. 1-4. IEEE, 2009

[19] M. Chakraborty, B. Rana, P. P. Sarkar, and D. Achintya "Size reduction of a rectangular microstrip patch antenna with slots and defected ground structure." International Journal of Electronics Engineering 4, no. 1 (2012): 61-64.

[20] K. P. Rao, P. V. Hunugund and R. M. Vani, "Two element microstrip antenna array using square slot EBG structure for C-band applications," 2017 Innovations in Power and Advanced Computing Technologies (i-PACT), Vellore, 2017, pp. 1-5.

[21] S. Alam, I. G. N. Y. Wibisana and I. Surjati, "Miniaturization of array microstrip antenna using peripheral slits for wireless fidelity communication," 2017 15th International Conference on Quality in Research $(Q i R)$ : International Symposium on Electrical and Computer Engineering, Nusa Dua, 2017, pp. 91-95 